\title{
Optical and Chemical Properties of Fragaria ananassa and Galena: Potential Photosensitizers in a Natural Dye-Sensitized Solar Cell
}

\author{
Ibukun S Akinsola ${ }^{1,2 *}$, Aderemi B Alabi ${ }^{1}$ and Coppede Nicola ${ }^{3}$ \\ ${ }^{1}$ Department of Physics, University of Ilorin, P.M.B. 1515, Ilorin, Nigeria. \\ ${ }^{2}$ Crown-Hill University, Eiyenkorin, P.M.B. 1605, Ilorin, Nigeria. \\ ${ }^{3}$ Institute of Materials for Electronics and Magnetism, Parco Area delle Scienze, 37/A, 43124, \\ Parma, PR, Italy. \\ *Corresponding author: siakinsola711@gmail.com \\ Co-authors'email: remi050970@gmail.com (Alabi); nicola.coppede@gmail.com (Nicola) \\ Received 1 Jul 2021, Revised 16 Oct 2021, Accepted 23 Oct 2021, Dec 2021 \\ DOI: https://dx.doi.org/10.4314/tjs.v47i5.2
}

\begin{abstract}
Dye is one of the major components for high power conversion efficiency in a dye-sensitized solar cell. There are challenges natural dyes encounter, especially with quick degradation of the dye molecules. This work considered mineral dye in comparison with plant dye to address the challenge of degradation of natural plant dyes. The optical properties and functional groups of the two natural dyes were studied in this work. The absorption spectra, the optical band gaps and the absorption coefficients of the dyes were reported and found to be suitable for use as photosensitizers in a dye-sensitized solar cell (DSSC), as they absorb in the visible region of the electromagnetic radiation. The functional groups were studied by carrying out Fourier transform infrared spectroscopy and the amine, carbonyl and hydroxyl groups present in both dyes confirmed promising material that can absorb solar radiation in the visible region (around $380-800 \mathrm{~nm}$ ) and which finds application in fabricating DSSC. The organic compositions in the mineral dye are studied via the gas chromatography-mass spectrometry and the results justify the observation from the FTIR spectroscopy. The properties observed, via the characterizations techniques used, confirm materials suitable for use as photosensitizers in fabricating DSSC.
\end{abstract}

Keywords: Plant dye, Mineral dye, Photosensitizer, Visible region, DSSC.

\section{Introduction}

Around the year 2017,approximately $1.8 \%$ of the global electrical energy was from photovoltaic (PV) devices and have vital prospects to have a key role in all major future energy matters with an installed capacity of about 5 Terawatts by 2050 (Le Donne et al. 2019). Silicon-based solar cells are still the most prominent in the photovoltaic markets. Its relative cost implications due to the high technological involvement of production, as compared with that of fossil fuels products, worth desiring an alternative route to harnessing solar energy via the photovoltaic technology. Hence, dyesensitized solar cell came to the rescue.

Dye-Sensitized Solar Cell (DSSC) has its origin from the suggestion of O'Regan and Gratzel and was categorized as the third generation of photovoltaic devices for the conversion of visible light into electrical energy (Monzir et al. 2017). Since the invention of the of dye-sensitized solar cells (DSSCs) in 1991, extensive researches are seriously taking place on DSSCs as alternatives to silicon-based solar cells, and even the thin film solar cells; due to their simple structures, transparency, flexibility 
and low production costs. Regardless of these advantages, the low efficiency of DSSC when compared to the long-ranged silicon-based cells is a limitation to their commercial implementation (Yang et al. 2014). Currently, DSSC has the potential of converting photons from sunlight to electrical energy at an efficiency of about $13 \%$, according to Ghann et al. (2017). Intensive efforts have been channelled towards the optimization of various components of DSSC with the aim of fabricating more efficient and stable cells.

Dye-sensitized solar cells which are liquid-based consist of the following: fluorine doped tin oxide front contact (FTO) on glass, nanoparticles photoanode covered in a monolayer of sensitizing dye, a hole conducting electrolyte, and graphite or platinum coated FTO counter electrode, which is the back contact. In Dye-sensitized solar cells, the dye is one of the key components for high power conversion efficiencies. In recent time, obvious progress has been achieved in the engineering of novel dye structures in order to enhance the performance of the system. For a while, ruthenium-based organic complexes have been the most stable and effective dyes used for DSSCs. Due to the fact that these dyes are characterized by toxicity, relative expensiveness, and difficult method of synthesis, increasing activities for using natural dyes have been reported (Ammar et al. 2019). These dyes show several merits when put side by side with the N-3 dye such as: a higher ground state $\mathrm{pK}_{\mathrm{a}}$ of the binding moiety which increases electrostatic binding onto the titanium dioxide surface at lower $\mathrm{pH}$ values, the decreased charge on the dye reducing the electrostatic repulsion between adsorbed dye units and hence increasing the dye loading, the oxidation potential of these dyes is shifted cathodically compared to that of the N-3 sensitizer, which increases the reversibility of the ruthenium III/II couple, and finally lead to enhanced stability.

Ghann et al. (2017) stated that the sensitizers which are currently used in production of solar cells are transition metal coordination complexes like ruthenium(II) carboxylatedpolypyridyl complexes, because of their high charge-transfer absorption within the entire visible range of electromagnetic radiation and highly efficient metal-ligand charge transfer transition (MLCT). However, Natural dyes are better desired than these synthetic dyes because of being more economical, easily attainable, abundant in supply and environmentally friendly. Also, they have large absorption coefficient due to molecular electronic transition allowed in them, which is $\pi$ to $\pi^{*}$ transitions. These pigments are derived from various plant parts such as flower petals, leaves, roots and fruits pulp/bark. The relatively quick degradation of even the natural dyes from plants as compared with the metal coordination complexes calls for consideration of an alternative natural dye with cost effectiveness and good stability. Natural dyes can be grouped into two: plant dyes and mineral dyes. In an attempt to find a way out of the quick degradation tendency of plant dyes, this study focuses on the comparative studies of properties of both the strawberry fruit plant dye and mineral dyes obtained from galena and their suitability in absorbing solar radiation for excitation of electrons in generating electricity if used to fabricate DSSC.

\section{Materials and Methods Materials}

The natural mineral, galena, was obtained from a community market around the location of study, Ilorin, Nigeria (Lat. $8.4928^{\circ} \mathrm{N}$, Long. $4.5962^{\circ} \mathrm{E}$ ). The galena is being used by ancient women as eye cosmetics, in some parts of Africa. The plant dye is from Fragaria ananassa (strawberry fruit). Figure 1 shows an image of galena.

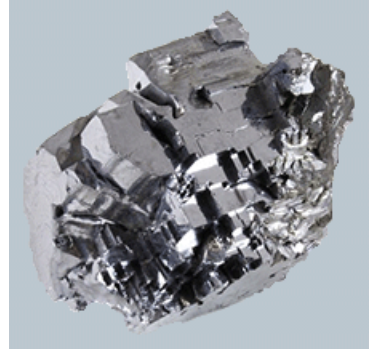

Figure 1: Image of galena (Source: http://www.rocksandminerals.com/lead.htm) 


\section{Methods}

The dye of the natural mineral was extracted separately from the powder using ethanol, with decantation technique. Strawberry fruit was cut into a desired weighted size, washed and crushed with mortar and pestle. It was then soaked in ethanol for about 1 hour for the extraction of the dye. The functional groups present in the dyes were determined using the Fourier Transform Infrared (FTIR) Spectrometer (Agilent Technologies, USA: CARY 630 FTIR). The absorption spectra of the dye were studied within the visible region of the electromagnetic radiation and it was done using the UV-visible Spectrophotometer (VWR: UV-6300PC Double Beam Spectrophotometer).

The dye's organic compositions were studied using the gas chromatography-mass spectrometer (Agilent Technologies-5975C Inert MSD with Triple Axis Detector). Helium was used as carrier gas. Comparative analytical method was employed by comparing the given spectrum to a spectrum library to see if its characteristics are present for some sample in the library. MSD-Mass selective detector was used. NIST-National Institute of Standards and Technology's Library Database was considered and compared.

\section{Results and Discussion \\ Optical properties \\ Absorption spectra}

The absorption spectra of the dyes considered are presented in Figure 1. These were obtained from the UV-vis spectroscopy. Electromagnetic spectrum comprises of radio wave, infrared, visible light, ultraviolet, $\mathrm{X}$ ray and gamma ray. The interest in this work is in visible region (about $380-800 \mathrm{~nm}$ ), since the dye is considered as photosensitizer in a Dye-Sensitized Solar Cell (DSSC) which absorbs solar radiation within the visible region of the electromagnetic radiation.

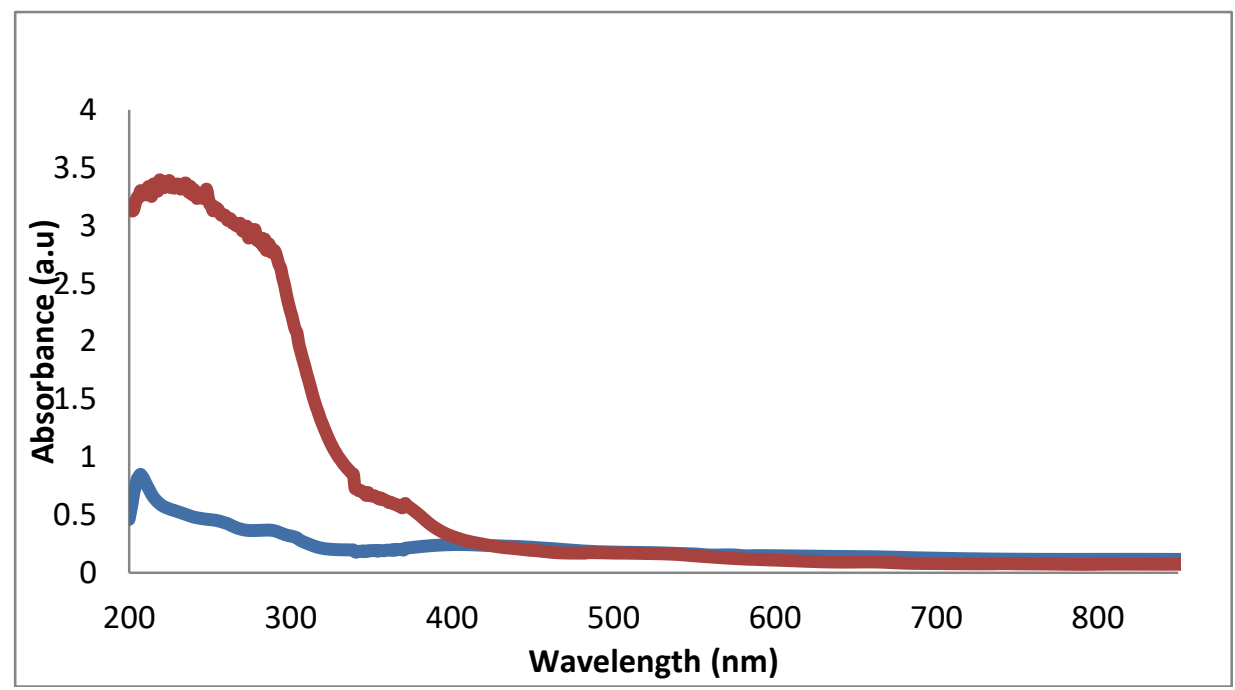

Figure 2: Comparative absorption spectrum of dyes (Galena-blue; Strawberry-red).

From the spectra, it can be seen that there is absorption of light in the visible region by the two dyes. The absorption peaks observed at the ultraviolet regions (around $210 \mathrm{~nm}$ to $370 \mathrm{~nm}$ ) could be as a result of the absorption by the organic components (the flavonoids) in the plant dyes. It was observed that the mineral dye has slightly higher absorption of solar radiation within the visible region than the strawberry dye which has been projected as an efficient natural dye over the years for DSSC due to its pigment colour. The summary of few of the absorbance values of absorption peaks at wavelengths within the visible region is presented in Table 1 . From Figure 2, it can be seen that the two dyes 
coincide at around $519 \mathrm{~nm}$ of wavelength, in terms of absorption peak (though galena is still seen to be slightly higher). Galena, a mineral dye is a promising material in serving as a photosensitizer in fabricating DSSC.

Considering Figure 3, the absorption of solar radiation, based on the absorbance values of a typical ruthenium-based dye (a synthetic dye), is relatively low (at the wavelength of the peaks) with respect to this mineral dye; which shows a higher absorption. They are indeed promising photosensitizer in DSSC, as substitute to dyes of plants sources. Ruthenium-based dye exhibits ligand-centred charge transfer (LCCT) transitions $\left(\pi-\pi^{*}\right)$ as well as metalto-ligand charge transfer (MLCT) transitions $\left(4 d-\pi^{*}\right)$ that can be observed in the absorption spectra of N-719 dye (See Figure $3)$. The absorption bands at lower energies represent the MLCT transitions $\left(\lambda_{1}\right.$ and $\left.\lambda_{2}\right)$, whereas the more energetically demanding transitions $\left(\lambda_{3}\right.$ and $\left.\lambda_{4}\right)$ correspond to LCCT transitions. Promotion of an electron from $\pi-$ bonding orbital to an antibonding $\pi$ orbital* is represented by $\pi-\pi^{*}$ molecular electronic transition. The section of molecules which can undergo such detectable electron transitions can be referred to as chromophores, owing to the fact that such transitions absorb electromagnetic radiation (light), which may hypothetically be perceived as colour spectra.

Table 1: summarized wavelengths values for different absorption peaks in the dye samples

\begin{tabular}{|l|l|l|}
\hline Dye & $\begin{array}{l}\text { Wavelength } \\
(\mathrm{nm})\end{array}$ & $\begin{array}{l}\text { Absorbance } \\
\text { values (arb. } \\
\text { unit) }\end{array}$ \\
\hline Galena & 405 & 0.243 \\
& 578 & 0.149 \\
\hline Strawberry & 509 & 0.168 \\
\hline
\end{tabular}

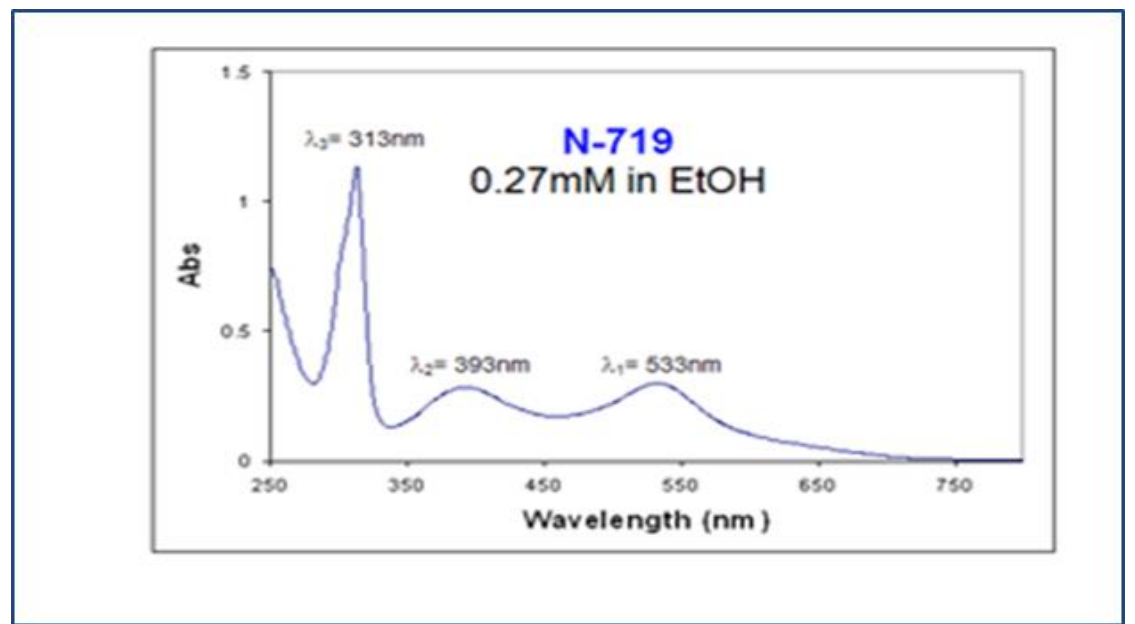

Figure 3: Absorption spectrum of ruthenium-based dye, N-719 (Product No. 703214) (Source: Hans and Yanek 2017).

The absorption spectra of galena dye in Figure 2 shows absorption bands at more energetically demanding transitions. This corresponds to LCCT transitions within the visible region. Hence, it favours good absorption of solar radiation for the operation of a solar cell. Invariably, we have a scientifically reliable mineral-sourced dye for exploration in fabricating DSSC.
Although, regardless of the variations in the absorbance of the dyes characterized, all of them showed a promising material for absorption of solar radiation.

\section{Absorption coefficient}

The absorption coefficient characterizes how far into a material, the light of a particular wavelength can penetrate before it is absorbed. The expression in Equation (1) is used to estimate the absorption coefficient of 
all the dyes used in this research (Ade et al. 2020);

$$
\alpha=4 \pi k / \lambda
$$

where $\alpha=$ absorption coefficient, $\lambda=$ wavelength of peak absorbance, $\mathrm{k}=$ Boltzmann's Constant (in eV).

The summary of estimated absorption coefficients of the dyes characterized is shown in Table 2. Comparing Tables 1 and 2, it can be concluded that higher absorbance value indicates lower absorption coefficient and vice versa. The brief explanation given on absorption coefficient connotes that the farther light can penetrate in a dye before it is being absorbed, the better excitation of electrons which will take place in the dye, and hence the more effective the dye will be in causing charge separation in the semiconductor material to be used for fabricating DSSC.

Table 2: Estimated absorption coefficient of dyes

\begin{tabular}{|l|l|l|}
\hline Dye & $\begin{array}{l}\text { Wavelength } \\
\text { of peak } \\
\text { absorbance } \\
(\mathrm{nm})\end{array}$ & $\begin{array}{l}\text { Absorption } \\
\text { coefficient } \\
\left.\mathrm{m}^{-1}\right)\end{array}$ \\
\hline Galena & 405 & 2.670 \\
\hline Strawberry & 400 & 2.709 \\
\hline
\end{tabular}

\section{Optical band gap}

The optical band gap of the dyes used was obtained from the report of Ossai et al. (2020) which is $E_{g}=\frac{h c}{\lambda_{t h}}$

Where $E_{\mathrm{g}}$ is band gap, $\mathrm{h}$ is Planck's constant, $\lambda_{\mathrm{th}}$ is threshold wavelength (the offset absorption wavelength), $c$ is speed of light.
The estimated optical band gap is presented in Table 3. From the results obtained, it was observed that the higher the offset absorption wavelength (in $\mathrm{nm}$ ), the lower the band gap of the dye. This is likely to be due to the fact that as the threshold wavelength approaches near Infrared region, the band gap reduces and consequentially, the efficiency of the cell it produces increases. This is in agreement with the results of Abdalla et al. 2019, where a cell of dye with band gap of $1.436 \mathrm{eV}$ is $4.92 \%$ efficient, while that of $4.197 \mathrm{eV}$ is $0.37 \%$ efficient.

Table 3: Optical band gap of dyes with their respective offset absorption wavelengths

\begin{tabular}{|l|l|l|}
\hline Dye & $\begin{array}{l}\text { Offset } \\
\text { Absorption } \\
\text { wavelength } \\
(\mathrm{nm})\end{array}$ & $\begin{array}{l}\text { Band gap } \\
(\mathrm{eV})\end{array}$ \\
\hline Galena & 725 & 1.70 \\
\hline Strawberry & 407 & 3.05 \\
\hline
\end{tabular}

The more a material absorbs in the visible region, in terms of the magnitude of the absorption peaks in the visible region of electromagnetic radiation, the less the optical band gap and hence the more effective it is in serving as photosensitizer in DSSC.

\section{Chemical properties}

The chemical properties discussed on these dyes centred on the functional groups present and the GC-MS analysis of the mineral dye. The functional groups were obtained from the Fourier Transform Infrared Spectroscopic results presented in Figures 4 and 5 for galena and strawberry, respectively. 


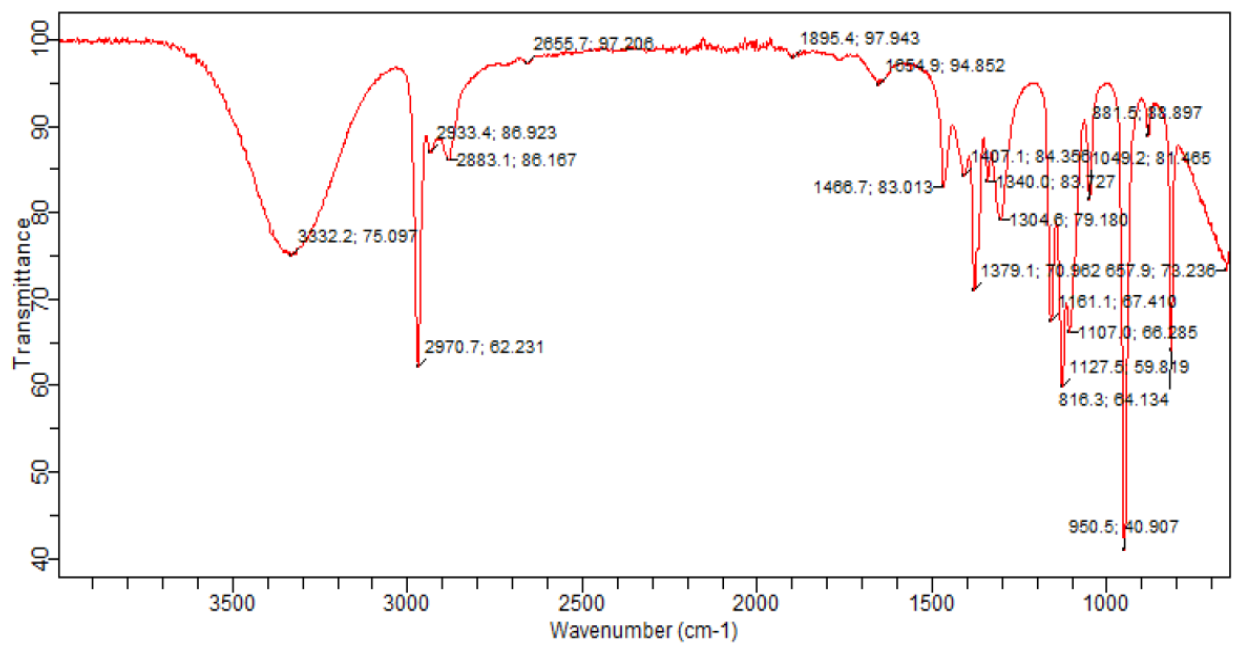

Figure 4: FTIR spectrum of galena dye.

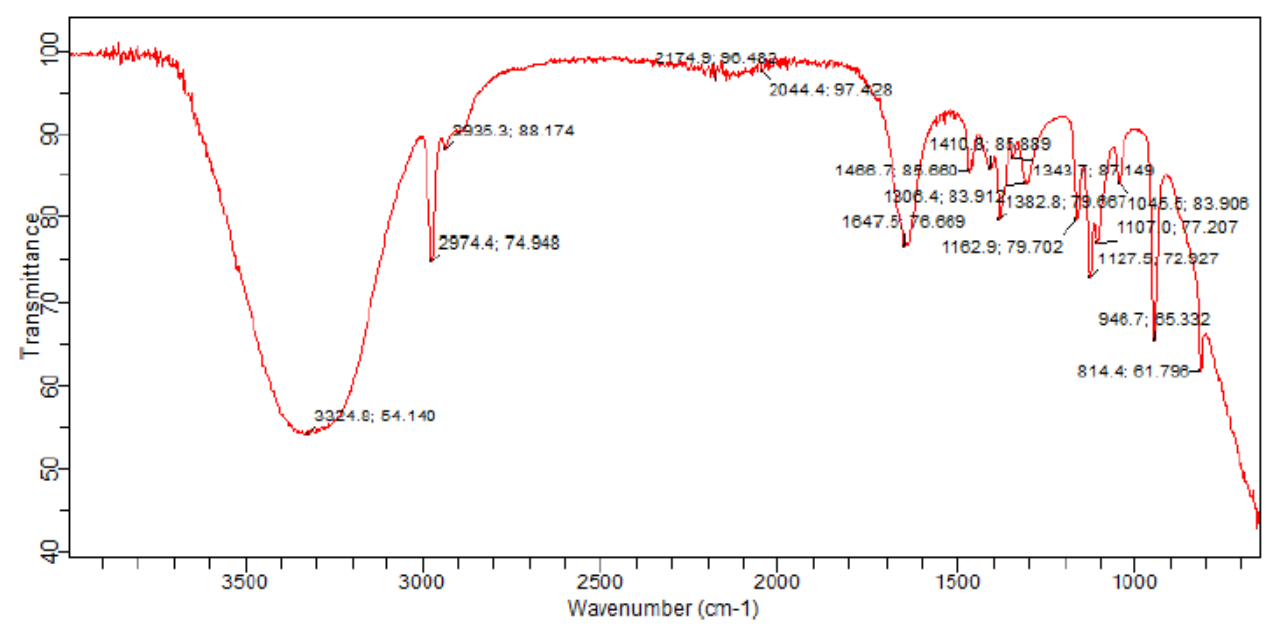

Figure 5: FTIR spectrum of strawberry dye.

The functional groups present in an organic dye, which are responsible for the absorption of solar radiation, are the amine, hydroxyl and the carbonyl groups. In addition to the high absorption coefficient of the dye in the visible region of the electromagnetic spectrum, the presence of hydroxyl and carbonyl anchoring groups in the galena dye as revealed by the stretching vibrations at $3332.2 \mathrm{~cm}^{-1}$ and $1654.9 \mathrm{~cm}^{-1}$, respectively will enable their adsorption unto the surface of semiconductor used in a DSSC. The presence of the amine group (N-H stretch, 1 per N-H bond) in the dye is revealed by the vibration at $3332.2 \mathrm{~cm}^{-1}$. This result is in agreement with report of Krishnamurthi et al. (2015) (of certain organic compounds). For strawberry dye, the analysis is also in Table 4. 
Table 4: Functional groups analysis in the dyes used

\begin{tabular}{|l|l|l|}
\hline Dye & Functional groups & Absorbance wavenumber $\left(\mathrm{cm}^{-1}\right)$ \\
\hline Galena & Hydroxyl $(-\mathrm{OH})$ & 3332.2 \\
& Carbonyl $(\mathrm{C}=\mathrm{O})$ & 1654.9 \\
& Amine $(\mathrm{N}-\mathrm{H})$ & 3332.2 \\
\hline Strawberry & Hydroxyl $(-\mathrm{OH})$ & 3324.8 \\
& Carbonyl $(\mathrm{C}=\mathrm{O})$ & 1647.5 \\
& Amine $(\mathrm{N}-\mathrm{H})$ & 3324.8 \\
\hline
\end{tabular}

The absorption bands for bending vibrations are typically found in the fingerprint region $\left(1400-600 \mathrm{~cm}^{-1}\right)$. These vibrations correspond to the likely metalbonded compounds present in the region.

The organic structural elucidation and chemical composition of the mineral dye was obtained using the gas chromatography-mass spectroscopic techniques (model: Agilent Technologies-5975C Inert MSD with Triple Axis Detector). The chromatogram of the mineral dye under study is presented in
Figure 6. By comparing the obtained spectrum with the NIST library database, the analyses of the organic compounds present in the material are summarized in Table 5. The essence of this is to ascertain the chemical compositions which are possibly responsible for absorbing solar radiation for excitation of electrons in the dye, in tandem with the functional groups that are present, for application in DSSC.

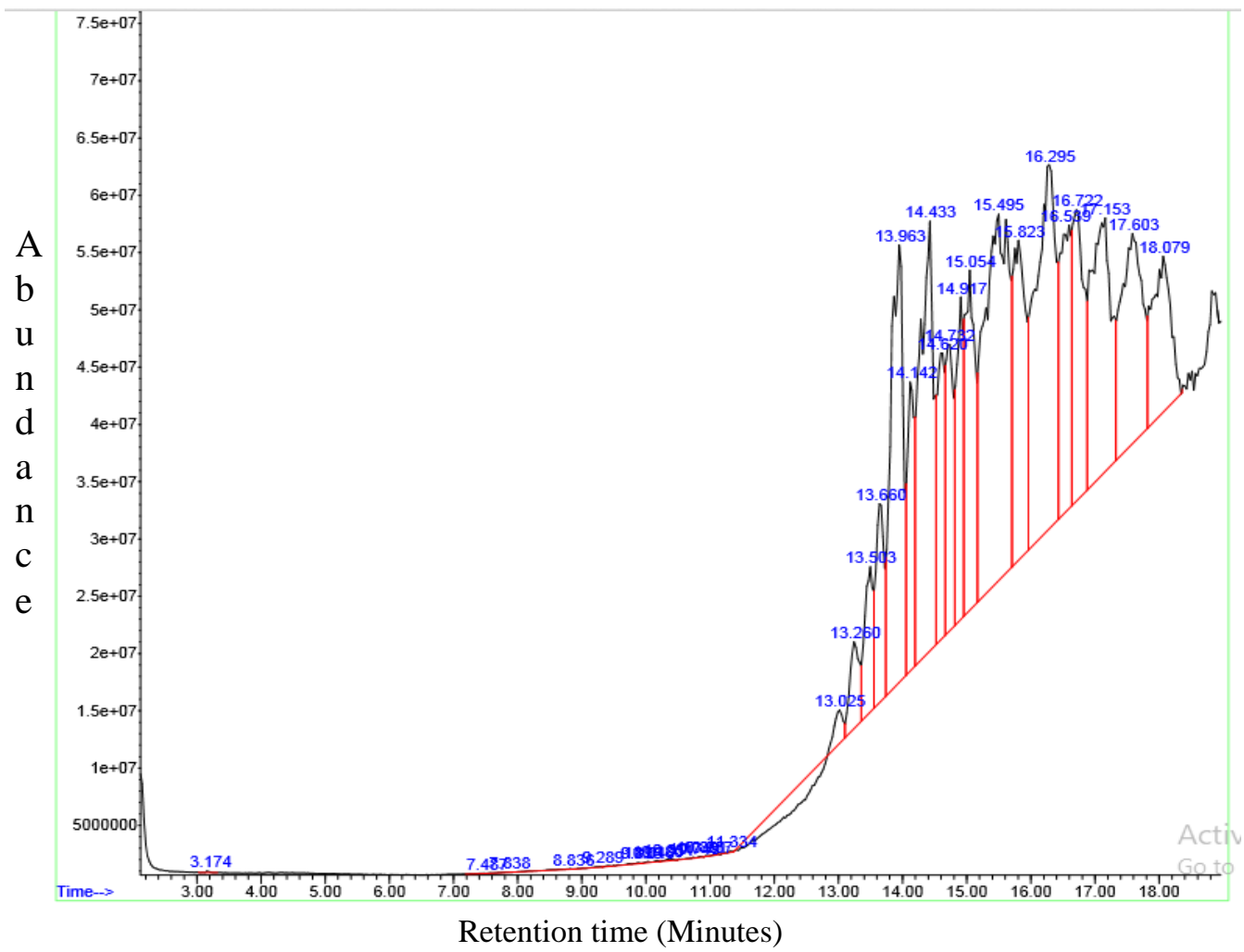

Figure 6: Galena chromatogram. 
Table 5: Analysis of organic compounds composition in galena

\begin{tabular}{|c|c|c|c|c|}
\hline $\begin{array}{l}\text { Dye } \\
\text { sample }\end{array}$ & $\begin{array}{l}\text { Abundance on } \\
\text { the } \\
\text { chromatogram }\end{array}$ & $\begin{array}{l}\text { Retention time } \\
\text { (RT) on given } \\
\text { spectrum } \\
\text { (mins) }\end{array}$ & $\begin{array}{l}\text { Retention } \\
\text { time (RT) on } \\
\text { spectrum } \\
\text { library } \\
\text { (mins) }\end{array}$ & $\begin{array}{l}\text { Substances/Compounds } \\
\text { present }\end{array}$ \\
\hline \multirow[t]{3}{*}{ Galena } & $5.7 \mathrm{E}+7$ & 13.963 & 13.975 & 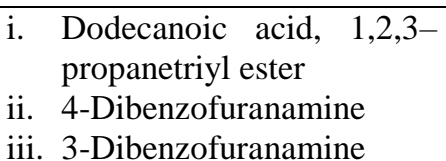 \\
\hline & $5.8 \mathrm{E}+7$ & 14.433 & 14.426 & $\begin{array}{l}\text { i. Dodecanoic acid, 2,3,4,6- } \\
\text { tetrachlorophenyl ester } \\
\text { ii. Fumaric acid, 2,3- } \\
\text { dichlorophenyl hexyl ester } \\
\text { iii. 4-Dibenzofuranamine }\end{array}$ \\
\hline & $6.2 \mathrm{E}+7$ & 16.295 & 16.285 & $\begin{array}{l}\text { i. Dodecanoic acid, 1,2,3- } \\
\text { propanetriyl ester } \\
\text { ii. } \begin{array}{l}\text { Dodecanoic acid, 2,3,4,6- } \\
\text { tetrachlorophenyl ester }\end{array} \\
\text { iii. } \\
\text { 4-Dibenzofuranamine }\end{array}$ \\
\hline
\end{tabular}

The ester family $(\mathrm{C}=\mathrm{O}$ stretch) in the mineral dyes buttress the presence of amide related, which is carbonyl stretching absorption. Dodecanoic acid, 1,2,3 propanetriyl ester $\left(\mathrm{C}_{39} \mathrm{H}_{74} \mathrm{O}_{6}\right)$ in the mineral dye aid good absorption of solar radiation in the visible region. Dodecanoic acid, 2,3,4,6tetrachlorophenyl ester confirms the hydroxyl group observed via the FTIR spectroscopy. 4Dibenzofuranamine $\left(\mathrm{C}_{12} \mathrm{H}_{9} \mathrm{NO}\right)$ is most likely for the amine group seen in the mineral's dyes. All these are suspected to be responsible for the behaviour of the dye with light. Therefore, the dye materials are potential photosensitizers than can be explored for enhancement of DSSC efficiency.

\section{Conclusion}

In this work, the properties of natural dyes which make them suitable as potential photosensitizers in a Dye-sensitized solar cell (DSSC) were studied. The mineral dye, though being for different applications for decades, is discovered to possess potential of being a good absorber of solar radiation in the visible region of electromagnetic radiation. The absorption coefficient reported also affirms this. The functional groups present in the dyes, which are amine, carbonyl and hydroxyl are the kinds which favour good absorption of photons. The optical properties of the dyes revealed energy band gap (in the range of 1.70-3.05 eV) which are for good absorbers in designing solar cells. Comparatively, the mineral dye behaves better than the plant dye, though both have properties which make them good photosensitizers in DSSC.

\section{Acknowledgements}

The authors appreciate the Departments of Chemistry and Chemical Engineering Laboratories, University of Ilorin, Nigeria for the characterizations carried there. The support of the Materials Science Laboratory, Department of Physics, University of Ilorin, Nigeria is highly appreciated.

\section{Declaration of Interest}

The authors declare that there is no conflict of interest whatsoever on this research work.

\section{References}

Abd-alla MD, Elkareem AAKA, MI Ahmed, Abdalsakhi SMH and RA Elgani 2019 The effect of optical energy gaps on the efficiency for DSSC by using Gum Arabic doped by $\mathrm{CuO}$ and (Coumarin 500, Ecrchom black, Rhodamine B and 
DDTTc) Dyes. Int. J. Innov. Res. Sci. Eng. Technol. 6(12): 38-46.

Ade ITK, Paulus LG, Andi ACT 2020 A study of efficiency improvement of dye sensitized solar cell (DSSC) organic extracted from mango leaves and ginger. Int. J. Sci. Eng. Res. 11(5): 1482-1486.

Ammar AM, Mohamed HS, Yousef MM, Abdel-Hafez GM, Hassanien AS and Khalil AS 2019 Dye-sensitized solar cells (DSSCs) based on extracted natural dyes. J. Nanomater. 2019: Article ID 1867271.

Ghann W, Kang H, Sheikh T, Yadav S, Chavez-Gil T, Nesbitt F and Uddin J 2017 Fabrication, optimization and characterization of natural dye sensitized solar cell. Sci. Rep. 7(1): 41470.

Hans D and Yanek H 2017 Ruthenium-based dyes for dye-sensitized solar cells. Dyesol Ltd., 3 Dominion Place, Queanbeyan NSW $2620 \quad$ Australia. http://www.rocksandminerals.com/lead.ht $\mathrm{m}$ (accessed on 27th September, 2019)
Krishnamurthi PP, Ramalingan HB, Raju K 2015 FT-IR studies of hydrogen bonding interaction between the hydroxyl and carbonyl liquids. Adv. Appl. Sci. Res. 6(12): 44-52.

Le Donne A, Trifiletti V and Binetti S 2019 New earth-abundant thin film solar cells based on chalcogenides. Front. Chem. 7: 297.

Monzir SA, Abuiriban MA and Dahoudi NA 2017 Dye-sensitized solar cells using fifteen natural dyes as sensitizers of nanocrystallineTiO ${ }_{2}$. Sci. Technol. Dev. 34(3): 135-139.

Ossai AN, Alabi AB, Ezike SC and Aina AO 2020 Zinc oxide- based dye- sensitized solar cells using natural and synthetic sensitizers. Curr. Res. Green Sustain. Chem. 3: 100043.

Yang JH, Bark CW, Kim KH and Choi HW 2014 Characteristics of the dye-senstized solar cells using $\mathrm{TiO}_{2}$ nanotubes treated with $\mathrm{TiCl}_{4}$. Materials 7(5): 3522-3532. 